\title{
Transcriptional Patterns of Biogeochemically Relevant Marker Genes by Temperate Marine Bacteria
}

OPEN ACCESS

Edited by: Osvaldo Ulloa,

University of Concepción, Chile

Reviewed by:

David L. Kirchman,

University of Delaware, United States Anthony David Bertagnolli, Georgia Institute of Technology,

United States

${ }^{*}$ Correspondence:

Laura Alonso-Sáez lalonso@azti.es

Specialty section: This article was submitted to

Aquatic Microbiology,

a section of the journal

Frontiers in Microbiology

Received: 17 July 2019 Accepted: 04 March 2020 Published: 20 March 2020

Citation:

Alonso-Sáez L, Morán XAG and González JM (2020) Transcriptional Patterns of Biogeochemically Relevant Marker Genes by Temperate Marine Bacteria. Front. Microbiol. 11:465. doi: 10.3389/fmicb.2020.00465

\author{
Laura Alonso-Sáez ${ }^{1,2 *}$, Xosé Anxelu G. Morán ${ }^{3}$ and José M. González ${ }^{4}$ \\ 'Marine Research Division, AZTI, Sukarrieta, Spain, ${ }^{2}$ Centro Oceanográfico de Gijón/Xixón, Instituto Español \\ de Oceanografía (IEO), Gijón/Xixón, Spain, ${ }^{3}$ Biological and Environmental Sciences and Engineering Division, Red Sea \\ Research Center, King Abdullah University of Science and Technology (KAUST), Thuwal, Saudi Arabia, ${ }^{4}$ Department \\ of Microbiology, University of La Laguna, La Laguna, Spain
}

Environmental microbial gene expression patterns remain largely unexplored, particularly at interannual time scales. We analyzed the variability in the expression of marker genes involved in ecologically relevant biogeochemical processes at a temperate Atlantic site over two consecutive years. Most of nifH transcripts, involved in nitrogen $(\mathrm{N})$ fixation, were affiliated with the symbiotic cyanobacterium Candidatus Atelocyanobacterium thalassa, suggesting a key role as $\mathrm{N}$ providers in this system. The expression of nifH and amoA (i.e., marker for ammonia oxidation) showed consistent maxima in summer and autumn, respectively, suggesting a temporal succession of these important $\mathrm{N}$ cycling processes. The patterns of expression of genes related to the oxidation of carbon monoxide (coxL) and reduced sulfur (soxB) were different from that of amoA, indicating alternate timings for these energy conservation strategies. We detected expression of alkaline phosphatases, induced under phosphorus limitation, in agreement with the reported co-limitation by this nutrient at the study site. In contrast, low-affinity phosphate membrane transporters (pit) typically expressed under phosphorus luxury conditions, were mainly detected in post-bloom conditions. Rhodobacteraceae dominated the expression of soxB, coxL and ureases, while Pelagibacteraceae dominated the expression of proteorhodopsins. Bacteroidetes and Gammaproteobacteria were major contributors to the uptake of inorganic nutrients (pit and amt transporters). Yet, in autumn, Thauma- and Euryarchaeota unexpectedly contributed importantly to the uptake of ammonia and phosphate, respectively. We provide new hints on the active players and potential dynamics of ecologically relevant functions in situ, highlighting the potential of metatranscriptomics to provide significant input to future omics-driven marine ecosystem assessment.

Keywords: gene expression, metatranscriptomics, coastal, bacterioplankton, functional marker genes

\section{INTRODUCTION}

The analysis of marine protein-coding genes has undergone rapid expansion following the development of meta-omics technologies and its application to oceanic environments, from local to large-scale ocean surveys (Gilbert and Dupont, 2011; Moran et al., 2013; Salazar et al., 2019). The study of this vast repertoire of microbial functional genes is providing 
new perspectives on the ocean biogeochemistry, including the discovery of novel enzymes, pathways, and key microbial players (Zehr and Kudela, 2011; Ferrera et al., 2015). In this regard, the identification of marker genes, highly specific for some metabolic functions, has been key to address the abundance, diversity and geographic extent of microbes involved in biogeochemically relevant processes, such as nitrification (amoA genes, Francis et al., 2005; Sintes et al., 2013), nitrogen fixation (nifH genes; Zehr et al., 2003), or carbon monoxide oxidation (cox genes; King and Weber, 2007).

As compared to the oceanic distribution of these functional marker genes (as targeted by metagenomics), our knowledge on their gene expression patterns has grown at a slower pace. In one the first applications of metatranscriptomics to aquatic environments, some biogeochemically relevant processes such as bacterial assimilation of $C_{1}$ compounds and the oxidation of sulfur (S) compounds were found to be active at a coastal Atlantic salt marsh (Poretsky et al., 2005). Related with $\mathrm{C}_{1}$ metabolism, carbon monoxide $(\mathrm{CO})$ is an important greenhouse gas, which in marine systems is mainly produced by photochemical degradation of organic matter. Thus, the uptake of this compound by marine bacteria can substantially reduce its oceanic emissions to the atmosphere (King and Weber, 2007). Even if the marker genes for $\mathrm{CO}$ oxidation ( $\operatorname{cox} L)$ are abundant in the environment (Cordero et al., 2019), reports of their expression in marine waters are still scarce (Georges et al., 2014). Also linked to climate, dimethylsulfoniopropionate (DMSP) is a source of $\mathrm{C}$ and reduced $\mathrm{S}$ for marine microorganisms, and the precursor of the climate-cooling gas DMS (Yoch, 2002). While the production of DMS from DMSP was first described in Rhodobacteraceae, other key players in this process, such as some members of Gammaproteobacteria, have been identified by experimental metatranscriptomics (Vila-Costa et al., 2010).

In the context of the nitrogen $(\mathrm{N})$ cycle, studies targeting the functional marker genes amoA (for ammonia oxidation) and nifH (for nitrogen fixation) have drastically increased our knowledge on the magnitude of these two processes in the ocean. In the former case, the sequencing of some of the first marine metagenomes retrieved amo sequences of archaeal origin (Venter et al., 2004), challenging the previous assumption that this function was exclusively carried out by a few members of Gamma- and Betaproteobacteria (Ward et al., 2007). Subsequent studies have found that Archaea actually dominate the oxidation of ammonia in the ocean, expanding the geographical distribution of this process to the extensive mesopelagic and bathypelagic realms (Wuchter et al., 2006; Sintes et al., 2013, 2016). In the second case, biological $\mathrm{N}$ fixation, which reduces atmospheric $\mathrm{N}_{2}$ to biologically available ammonium, supplies this essential nutrient to aquatic ecosystems. First thought to be dominated by the filamentous bloom-forming cyanobacteria Trichodesmium, this process is now known to be mediated mainly by widespread unicellular $\mathrm{N}_{2}$ fixers in the open ocean (such as Candidatus Atelocyanobacterium thalassa and Crocosphaera watsonii, Zehr, 2011). Additionally, there is evidence of heterotrophic bacteria involved in this process (Bombar et al., 2016). These findings have changed the size class of the dominant diazotrophs in the ocean, with implications in the fate of fixed $\mathrm{N}$ in marine food webs. Determining the spatial coverage and temporal activity of these widespread, abundant unicellular diazotrophs would be a key step toward filling the large gaps in our oceanic global $\mathrm{N}_{2}$ fixation estimates.

In general, marine metatranscriptomic studies have helped uncover the key microbial players involved in different biogeochemical processes, and where in the ocean they become active. Yet, identifying the temporal patterns in the expression of globally relevant functional genes remains one of the main gaps in knowledge (Salazar et al., 2019). While there are evidences of diel oscillations in marine microbial expression patterns (Poretsky et al., 2009b; Ottesen et al., 2014; Aylward et al., 2015), few studies have addressed gene expression patterns at longer timescales (e.g., monthly, inter-annually; but see Gifford et al., 2014; Hollibaugh et al., 2014). Here, we carried out an analysis of a metatranscriptomic dataset obtained over two consecutive years in surface waters at a temperate mid-shelf station in the southern Bay of Biscay (NE Atlantic). Our aims were (i) to identify key biogeochemical pathways that were active at the study site by following the expression dynamics of functional marker genes, (ii) to analyze the composition of transcriptionally active taxa involved in these functions, and (iii) to understand the variability in their expression levels under environmental conditions ranging from oligotrophic to mesotrophic, as typically found in temperate waters over the seasonal cycle.

\section{MATERIALS AND METHODS}

\section{Sample Collection}

Eight metatranscriptomic samples were collected in spring (April and/or May), summer (July) and autumn (November) over two consecutive years at the station Radiales E2 Gijón/Xixón $\left(43.67^{\circ} \mathrm{N}, 5.58^{\circ} \mathrm{W}\right)$ in the Southern Bay of Biscay. For consistency with previous studies on the same dataset (e.g., Alonso-Sáez et al., 2015, 2018), a sample collected in early May in 2012 (2nd May) has been designated "April 2012," to distinguish it from a second sample taken in late May (23rd May, see Supplementary Table S1). Ancillary variables (temperature, salinity, chlorophyll $a$, bacterial cell abundance and heterotrophic prokaryotic production) were measured as explained in ArandiaGorostidi et al. (2017). Samples for RNA analysis (from 4.5 to $11 \mathrm{~L}$ ) were collected from a depth of $5 \mathrm{~m}$ and immediately filtered using 3- $\mu \mathrm{m}$ pore-size polycarbonate pre-filters and 0.22 $\mu \mathrm{m}$ pore-size polycarbonate filters (GTTP, Millipore). The 0.22 $\mu \mathrm{m}$ filters were placed in Whirl-Packs containing $2 \mathrm{~mL}$ of RLT buffer (Qiagen, Valencia, CA), flash frozen in liquid nitrogen, and stored at $-80^{\circ} \mathrm{C}$. Time from sample collection to flash freezing of the filters ranged between 15 and $20 \mathrm{~min}$. Samples were taken around midday (1-3 $\mathrm{h}$ after noon), to minimize biases in the interpretation of the results due to differences in diel transcription patterns (Poretsky et al., 2009b).

\section{RNA Processing}

RNA was extracted as previously detailed (Poretsky et al., 2009a). Briefly, filters were shattered with a mallet, vortexed in falcon tubes containing Power Soil beads (Mobio), and the lysate was 
mixed with $70 \%$ ethanol (1:1 volume). RNA extractions were carried out with the RNeasy Mini Kit (Qiagen). RNA was treated with Turbo DNase (Ambion) and the ribosomal RNA was depleted using the mRNA-only isolation kit (Epicenter), the MicrobeExpress, and MicrobeEnrich kits (Ambion). The enriched mRNAs were linearly amplified using the Message Amp II-Bacteria kit (Ambion), reverse transcribed to doublestranded complementary DNA (cDNA) with the Universal Riboclone cDNA synthesis system (Promega) and purified with the QIAQuick PCR purification kit (Qiagen). The eight cDNA samples were subjected to single-end sequencing in an Illumina MiSeq run.

\section{Bioinformatics Analysis}

After an initial quality trimming of the reads, ribosomal RNAs (rRNAs) were removed from the dataset after identifying them by a BLASTn search using a SILVA reference database. The sequence of phiX174, used as a control in Illumina platforms, was also removed prior to further analyses. The remaining non-rRNA sequences were annotated using two different workflows. First, for a preliminary identification of functional marker proteincoding genes and top-hit taxonomic bins, all putative mRNAs were queried (BLASTx, bitscore cutoff $\geq 40$, Altschul et al., 1990) against the National Center for Biotechnology Information's (NCBI) RefSeq database (version 63, January 2014), which includes proteins from viruses and all three domains of life. The annotations of the BLASTx top-hits were screened by textbased queries to search for specific functional genes following Gifford et al. (2013). Next, a subset of mRNAs representing an even coverage among samples (201510 sequences each) were queried by BLASTx (bitscore cutoff $\geq 40$ ) against a custom RefSeq database where peptides of interest were reannotated using hidden Markov models run with HMMER3 (Eddy, 2008). The list of genes selected fulfilled two criteria: (i) high specificity for the corresponding function of interest (to avoid targeting genes with ambiguous functions or potentially involved in several metabolic processes) and, (ii) being represented by a single protein family easily recognizable by bioinformatic methods. Based on this selection, the protein families TIGR01287, TIGR01792, TIGR04486, TIGR01115, and TIGR00842 were used to search NifH, UreC, SoxB, PufM, and BCCT, respectively. PF05787, PF09423, and PF01384, were used for PhoX, PhoD, and Pit transporter searches, respectively. Finally, PF01315, PF00909, PF12942, and PF01036 were used for CoxL, amt transporters, archaeal AmoA and proteorhodopsin (PR) searches, respectively. TIGR03080 was used to search for bacterial AmoA, but no hits were found in our metatranscriptomes. A PFAM or TIGRFAM hit was considered valid if its score was equal to or bigger than the recommended gathering score for the hidden Markov model. The label of the peptides in the RefSeq sequence file was modified to accommodate the new annotation based on hits to protein families. In the case of CoxL, we additionally looked for the signature sequence "AYxCSFR" at the active site of the enzyme, a motif present only in Form I Carbon Monoxide Dehydrogenases $(\mathrm{CODH})$. Thus, CODH Form II enzymes, which may not be primarily involved in CO oxidation (King and Weber, 2007), were not targeted in the analyses. In the case of the Pit and PR, a preliminary search against PATRIC protein families (Wattam et al., 2013) identified a substantial number of hits of euryarchaeal origin. Thus, euryarchaeal peptides were incorporated to the protein database as they were absent from RefSeq. The microbial taxa involved in each marker gene expression were identified using MEtaGenome Analyzer (MEGAN, Huson et al., 2007), to obtain consensus taxonomic assignments.

\section{RESULTS AND DISCUSSION}

The temperate station of study (E2-Gijón/Xixón, $100 \mathrm{~m}$ maximum depth) is a long-term monitoring site (Morán et al., 2015) located ca. $13.5 \mathrm{~km}$ off the Spanish coast. This site is characterized by a late winter/early spring phytoplankton bloom, followed by summer thermal stratification and autumn remixing of the water column, like most of the northern Iberian Peninsula continental shelf (Bode et al., 1996; Morán et al., 2015). Samples for mRNA analysis were collected at different seasonal periods over two consecutive years, with the aim of covering a wide range of oceanographic conditions, from oligotrophic (summer stratification) to mesotrophic (mixing periods, Figure 1). Summer and autumn samples differed substantially in temperature and chlorophyll $a$ concentration over the 2 years but shared relatively low levels of cellspecific heterotrophic bacterial production (Figure 1). Bacterial production was maximum in spring, concomitant with a declining trend in chlorophyll a concentration, characteristic of post-bloom scenarios (Figure 1). However, the two spring periods analyzed showed important differences in terms of bacterial abundance and cytometric profiles. An unusually low abundance of low-nucleic-acid cells in situ was found in May 2012 (Figure 1), reaching minimum levels in the first 10-years of the time-series at the study site (Morán et al., 2015). This change was also reflected in the taxonomic composition of bacterial communities in spring 2012, clearly differing from the two previous spring periods (Alonso-Sáez et al., 2015). This suggests that the spring samples collected in 2012 were rather atypical in environmental and/or biotic conditions, which resulted in a large year-to-year variation in the expression profiles in that season. In this line, the relative contributions of the 50 tophit taxonomic bins to the transcript pool were highly correlated in samples taken in autumn or summer, but not in spring (Supplementary Figure S1).

From the 4.26 million reads identified as non-rRNA transcripts in the metatranscriptomes, $61 \%$ had significant hits in the RefSeq protein database (Supplementary Table S1). In a preliminary BLASTx search, several genes involved in ecologically relevant metabolic pathways (Moran, 2008) were detected at various expression levels in our dataset (Supplementary Table S2). We subsequently focused on a reduced set of well-studied marker genes, highly specific for environmentally relevant functions (Ferrera et al., 2015), and represented by single protein families, which would allow a robust method of detection (following Palovaara et al., 2014). These marker genes belonged to six main categories: photoheterotrophy (PR, pufM), oxidation of 


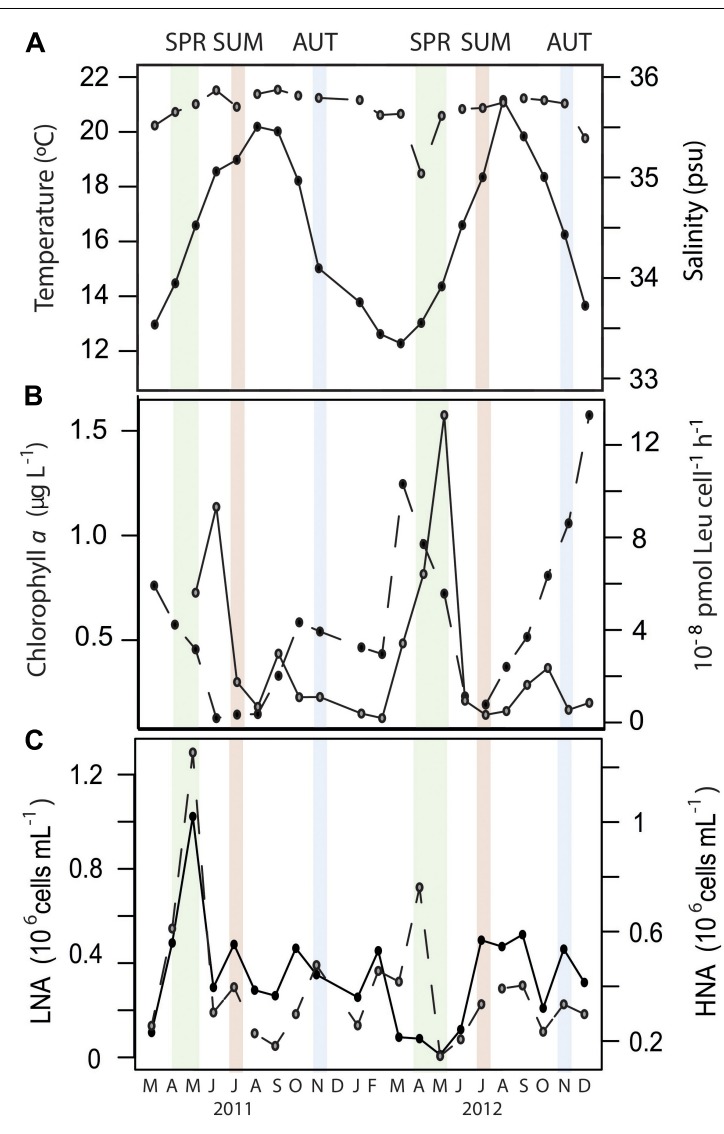

FIGURE 1 | Monthly data at the surface of the study station (E2-Gijón/Xixón) from March 2011 until December 2012 for (A) surface temperature (closed circles) and salinity (open circles); (B) Chlorophyll a concentration (closed circles) and cell-specific bacterial heterotrophic production (open circles); (C) Abundance of low- nucleic acid (LNA, closed circles) and high-nucleic acid (HNA, open circles) cells. Months when samples for metatranscriptomic analyses were collected appear highlighted in colors (green for spring, red for summer and blue for autumn).

inorganic compounds ( $\operatorname{cox} L$, amoA, and $\operatorname{sox} B$ for carbon monoxide, ammonia and sulfide/thiosulfate oxidation, respectively), nitrogen acquisition ( $n i f H$, ure $C$, and $a m t$, for nitrogenases, ureases and ammonia membrane transporters, respectively), phosphate acquisition (the extracellular alkaline phosphatases phoX and phoD, and the low-affinity phosphate membrane transporter pit) and reduced $S$ acquisition (the Betaine/Carnithine/Choline BCCT family transporter involved in DMSP incorporation, Sun et al., 2011).

Due to our limited sequencing depth, we could not appropriately capture rare transcripts. Yet, the coverage should be enough for a fair representation of frequently transcribed genes from relatively abundant taxa. Most of the main representatives in the metatranscriptomes were dominant members of surface bacterial communities in temperate waters (i.e., Pelagibacteraceae, SAR116, Rhodobacteraceae, Flavobacteriaceae, etc., Supplementary Figure S1). Some of these taxa showed recurrent seasonal dynamics at station E2 (e.g., Prochlorococcus, Rhodobacteraceae), while the dominant taxa affiliated with Pelagibacteraceae did not show any significant seasonality (Alonso-Sáez et al., 2015). A drastic decrease in the abundance of Pelagibacteraceae was found in samples collected in spring 2012 (Alonso-Sáez et al., 2015), consistent with the atypical cytometric profiles found in those samples (Morán et al., 2015). This marked change in composition was mirrored by substantial changes in the expression of some marker genes, such as PRs (Figure 2). The PR gene was mainly expressed by Pelagibacteraceae and their transcripts showed minimum levels in spring 2012, when its expression was dominated by Gammaproteobacteria (including Thioglobus), Bacteroidetes and Euryarchaeota (Figure 3). We also found a significant correlation between PR transcripts and the abundance of SAR11 in situ (determined by $16 \mathrm{~S}$ rRNA amplicon sequencing in Alonso-Sáez et al., 2015, Spearman Rho $=0.83, p=0.015$, $n=8$ ). Similarly, in coastal waters of the San Pedro Channel, PR gene transcripts were generally dominated by SAR11 except for a sample collected during a spring algal bloom, where Gammaproteobacteria dominated PR transcripts (Sieradzki et al., 2018). Thus, our results support the idea that community turnover strongly impacts some gene transcriptional patterns (Salazar et al., 2019). Additionally, the regulation of PR genes is likely complex at the community level, as PR have been found to be constitutively expressed (Giovannoni et al., 2005; Riedel et al., 2010) or regulated in response to light, nutrients or physiologic conditions in different isolates (Gómez-Consarnau et al., 2007, 2016; Steindler et al., 2011; Akram et al., 2013) and in the environment (Lami et al., 2009). Here, we found a marginally significant negative correlation between PR expression levels and cell-specific bacterial production (Spearman Rho $=-0.71$, $n=7, p$-value $=0.088$ ), supporting the view that the expression of PRs may decrease under conditions of high $\mathrm{C}$ bioavailability (McCarren et al., 2010).

In comparison to PRs, the expression of the marker gene pufM, encoding the $M$ subunit of the Aerobic Anoxygenic Photosynthesis (AAP) reaction-center complex was very low (at least two orders of magnitude below PRs, Figure 2). However, the quantification of AAP activity may have been underestimated in our dataset as samples were always collected around midday and the expression of puf genes takes place mostly during the night (Wagner-Döbler and Biebl, 2006; Jeanthon et al., 2011; Voget et al., 2015). We did not recover any pufM transcripts in autumn (November), a season when the abundance of AAPs has been described to rapidly drop in Mediterranean waters, likely associated with decreases in temperature and light availability (Ferrera et al., 2014).

With regards to the $\mathrm{N}$ cycle, a temporal succession of the key processes nitrogen fixation and ammonia oxidation was suggested by the dynamics of nifH and amoA genes (Figure 2). In our dataset, most nitrogenase related transcripts (96\%) were affiliated with the unicellular symbiotic cyanobacterium Can. A. thalassa (previously UCYN-A, Thompson et al., 2012), sharing 93-100\% identities at the nucleotide level. A previous study had also detected UCYN-A in summer at a nearby marine site, by using a double Catalyzed Reporter Deposition Fluorescence In Situ Hybridization (CARD-FISH, Cabello et al., 2016). This taxon has been recognized as one of the most 


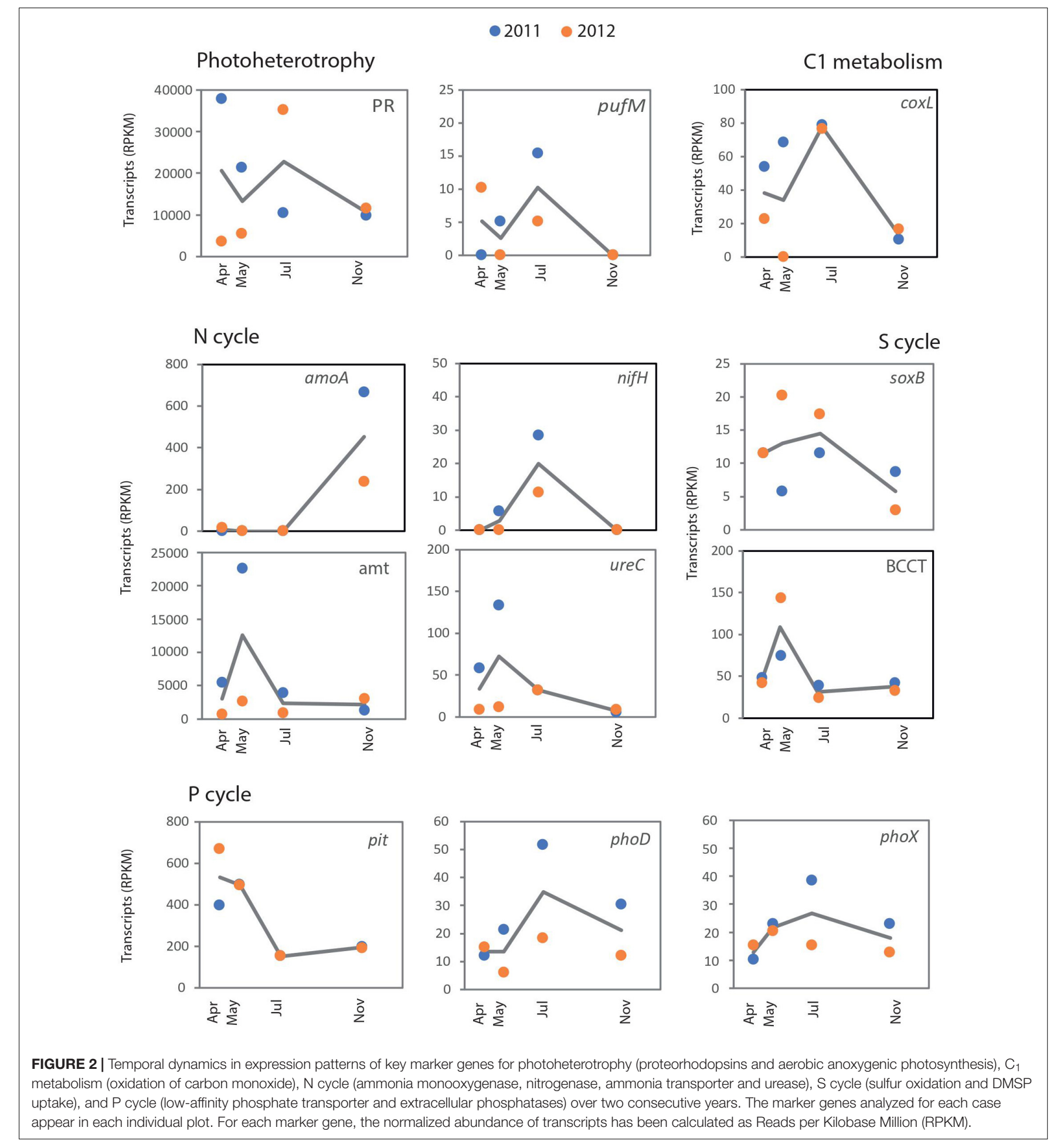

abundant nitrogen-fixing organisms in the surface open ocean (Martínez-Pérez et al., 2016), while some studies have shown a more widespread distribution, including deeper water layers and coastal environments (Moisander et al., 2010). As $\mathrm{N}$ fixation may shift the communities to $\mathrm{P}$ limitation, documenting the relevance of this process has important biogeochemical implications. At the station E2-Gijón/Xixón, evidence for $\mathrm{N}$ and P co-limitation of heterotrophic prokaryotes has been suggested for most of 2012 (with nitrate and phosphate concentration below 1 and $0.1 \mu \mathrm{moL} \mathrm{L}{ }^{-1}$, respectively, Morán et al., 2018). Yet, these conditions were not restricted to the summer months, when we detected nifH transcriptional activity, but comprised from May 


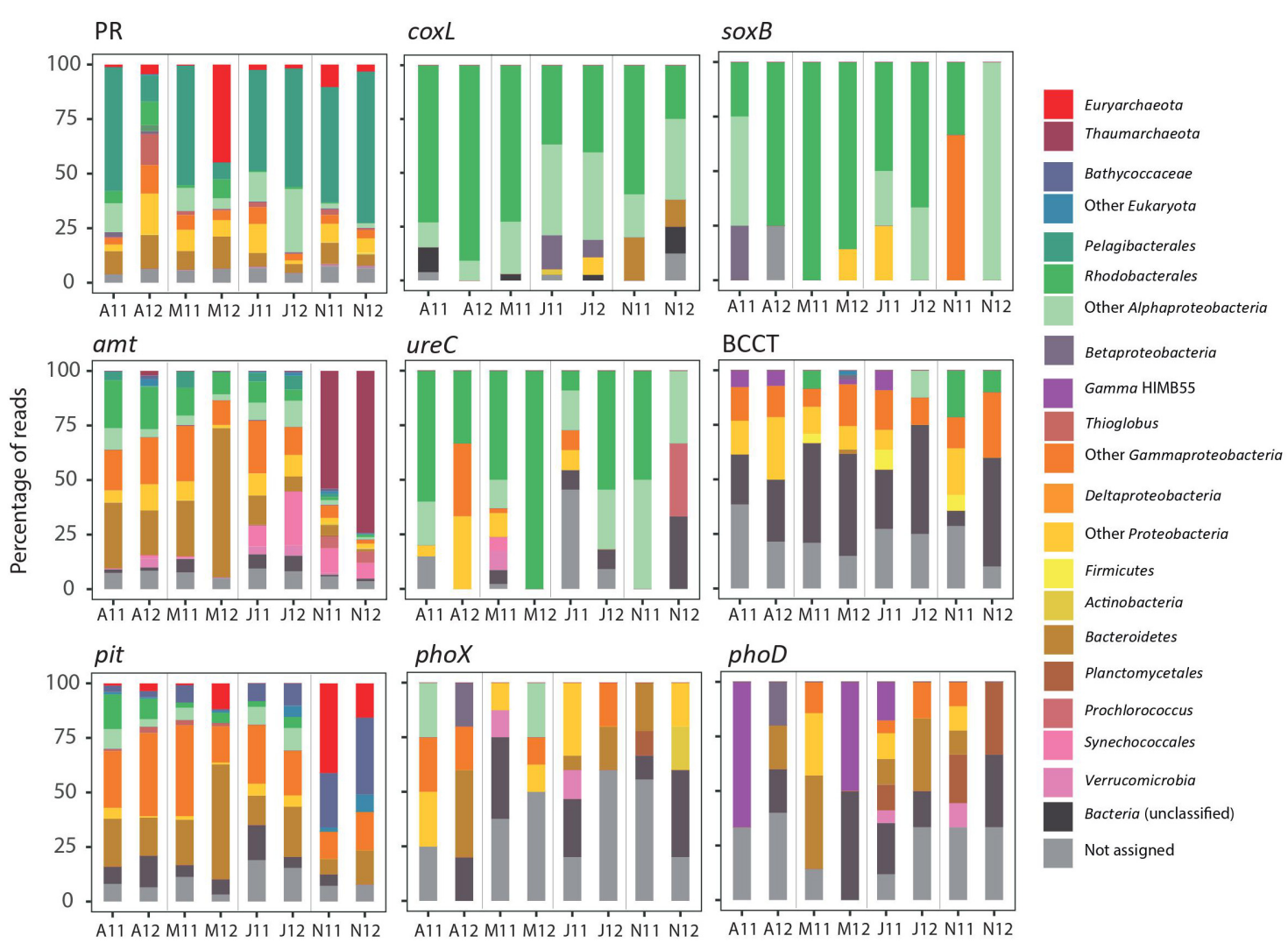

FIGURE 3 | Relative contribution of taxa involved in the expression of each of the marker genes analyzed in the spring (April, May), summer (July) and autumn (November) samples of two consecutive years. Consensus taxonomic bins have been identified using MEGAN software. Only genes which showed active expression in more than $50 \%$ of the samples are shown.

through November. In general, the response of Can. A. thalassa to nutrient availability in terms of $\mathrm{N}$ fixation and nif $H$ transcription has shown mixed responses, with no clear pattern (Turk-Kubo et al., 2012; Krupke et al., 2015). In a recent study, where the abundance of UCYN-A1 was analyzed in surface samples from the global ocean, no environmental factor clearly explained their distribution, but it was suggested that light availability may limit its growth (Cabello et al., 2016). Here, we found evidence that Can. A. thalassa were active in summer in mid-shelf waters, while supporting the observations that, in contrast to other unicellular diazotrophic cyanobacteria, they fix $\mathrm{N}$ during the day (Muñoz-Marín et al., 2019).

In contrast to the nifH expression dynamics, transcripts of another key enzyme of the $\mathrm{N}$ cycle was almost only found in autumn: the ammonia monooxygenase (amo) involved in archaeal nitrification (Wuchter et al., 2006). Interestingly, recurrent peaks of ammonia-oxidizing archaea have been found in autumn and winter in other coastal systems (Galand et al., 2010; Pitcher et al., 2011). While the ultimate reasons for such seasonal patterns remain unclear, the combination of temperature, nutrient availability, light and more recently, ROS sensitivity (Tolar et al., 2016), have been suggested as possible drivers of their dynamics. Presumably to fuel their nitrifying activity, Thaumarchaeota contributed significantly to the uptake of ammonia through the amt membrane transporter in autumn (up to $74 \%$ of total amt transcripts, Figure 3). Similarly, $\mathrm{N}$ acquisition proteins were dominant in thaumarchaeal transcripts in Sapelo Island waters (Hollibaugh et al., 2014). The high normalized transcript abundance of amoA, as compared to other genes (e.g., nifH, $\operatorname{sox} B$, coxL) indicates a very active transcriptional activity of Thaumarchaeota. This is remarkable given their low abundance in situ (on average only ca. $1 \%$ of cells as determined by CARD-FISH; Alonso-Sáez et al., 2015). These results agree with previous studies where Thaumarchaeota were also highly represented at the transcriptional level despite sustaining low-abundant populations (Church et al., 2010; Gifford et al., 2011), and suggests a key role for these microorganisms in the $\mathrm{N}$ biogeochemistry also in temperate systems.

While polar archaea can fuel nitrification by using urea (Alonso-Sáez et al., 2012), isolate-based studies have shown that the capability to use $\mathrm{N}$ from urea is not universal within Thaumarchaeota (Walker et al., 2010; Qin et al., 2014; Bayer et al., 2016). We did not detect transcripts of archaeal ureases at the E2 station, in agreement with the finding that ureases are more abundant in polar than temperate Thaumarchaeota (Tolar et al., 2016). However, a diversity of bacterial ureases was actively expressed, consistent with the idea that a large 
diversity of bacteria can use this compound (Collier et al., 2009; Solomon et al., 2010). Most ureolytic bacteria were affiliated with Rhodobacterales and other Alphaproteobacteria, but occasional active expression of Gammaproteobacteria and cyanobacteria was also found (Figure 3). Prochlorococcus was actively expressing ureC genes and amt transporters in autumn, in line with results from transcriptomic studies of the model strain Prochlorococcus sp. MED4, which expressed both mechanisms of $\mathrm{N}$ acquisition simultaneously (Zinser et al., 2009). While the relative abundance of $u r e C$ transcripts was lower than the widespread ammonia transporter $a m t$, it is still remarkable that the temporal dynamics of both transcripts was largely similar (Figure 2). This suggests that, from the temporal perspective, both substrates can be simultaneously incorporated by coastal marine bacteria as $\mathrm{N}$ sources.

In addition to nitrifiers, some marine microbes can oxidize other widespread substrates as an alternative energy source, such as carbon monoxide (CO) and inorganic S compounds. These processes were targeted by the marker genes encoding the $\mathrm{CO}$ dehydrogenase large subunit ( $\operatorname{cox} L$ ) and the sulfate thiohydrolase (soxB) of the Sox multi-enzyme pathway. Rhodobacterales were major contributors to the transcript pool of both soxB and coxL (Figure 3), confirming the view that members of this clade are central to the pelagic S cycling and CO metabolism (Buchan et al., 2005; Wagner-Döbler and Biebl, 2006). Transcripts of $\operatorname{cox} L$ and $\operatorname{sox} B$ genes showed very different dynamics as compared to $a m o A$, suggesting a different temporal partitioning of these energy-conservation strategies (Figure 2). The use of the supplementary energy gained by $\mathrm{CO}$ oxidation has previously been described as a strategy for coping with nutrient-poor conditions in Rhodobacteraceae (Moran et al., 2004), but the energetic benefits of oxidizing CO so far remain unclear (Cunliffe, 2013; Giebel et al., 2019). Here, we found an inverse relationship between coxL expression and chlorophyll a concentration (Spearman Rho $=-0.738, p=0.046, n=8$ ) as a proxy for trophic status, in agreement with the idea that bacteria can use CO to obtain extra energy under substrate limiting conditions.

Related with S metabolism, the expression of a DMSP transporter (BCCT) peaked both years in the phytoplankton decay period, characterized by potentially high availability of DMSP released from microalgae (Yoch, 2002). While most of the transcripts were not confidently assigned to any specific bacterial taxon, Gammaproteobacteria contributed ca. 20\% of BCCT transporter transcripts, some of them identified as HIMB55, a member of the OM60/NOR5 clade (Figure 3). Previous results using microautoradiography combined with FISH have shown that a taxonomically diverse suite of microbes is potentially involved in DMSP uptake, including some unidentified Gammaproteobacteria (Vila et al., 2004; Malmstrom et al., 2005; Motard-Côté et al., 2012). Our results by metatranscriptomics, together with those of Vila-Costa et al. (2010) support this view, and identified the gammaproteobacterium HIMB55 and Rhodobacterales as potentially active consumers.

Finally, regarding the phosphorus (P) cycle, a number of mechanisms for the acquisition of this element were analyzed. As $\mathrm{P}$ is a key component of cell macromolecules, prokaryotes have developed different strategies to incorporate it, such as the production of extracellular alkaline phosphatases to scavenge Pi from polymers. At least three prokaryotic alkaline phosphatase gene families have been described ( $p h o A$, phoD, and $p h o X$ ), which differ in substrate specificity and requirements of specific metal ions. The two most highly expressed extracellular phosphatases in marine waters are PhoD and PhoX (Luo et al., 2009; Sebastián and Ammerman, 2009), while the most classical PhoA is mainly intracellular, and likely playing a role in internal organophosphate hydrolysis. We found maximum abundance of both phoD and phoX transcripts in summer 2011. In contrast, the low-affinity $\mathrm{P}$ transporter pit clearly showed different dynamics, likely reflecting $\mathrm{P}$ availability conditions at the study site (Morán et al., 2018). As found elsewhere (Luo et al., 2009), most phoD and phoX transcripts remained uncharacterized at the taxonomic level (Figure 3), while Gammaproteobacteria and Bacteroidetes dominated pit transcripts. These groups include copiotrophic taxa with mechanisms of luxury $\mathrm{P}$ acquisition to meet their high demands for cellular energetics and growth. Thus, the dynamics of the pit transporter is likely associated with the presence of these taxa typically abundant in post-bloom conditions. Interestingly, in autumn, some picoeukaryotes (mainly Ostreococcus) and Euryarchaeota, an ecologically significant group with yet poorly known metabolic features (Zhang et al., 2015), jointly contributed more than $50 \%$ of pit transcripts, indicating their relevance in $\mathrm{P}$ cycling at that time of the year (Figure 3). Thus, our results indicate a so far unrecognized important role in nutrient cycling for Archaea in temperate waters. Often disregarded because of their low contribution to total prokaryotic abundance in surface waters, they may also represent key players in the biogeochemical cycling of coastal environments.

In summary, we have found evidence of active expression of diagnostic genes of some key microbial processes, such as nitrogen fixation, nitrification and carbon monoxide oxidation at a mid-shelf temperate site, which showed contrasting and occasionally recurrent patterns in their temporal dynamics. This suggests that the associated biogeochemical activities are liable to be affected by seasonally changing environmental conditions. We confirmed a prominent role of Thaumarchaeota in ammonia oxidation, Rhodobacterales in the use of alternative energy conservation strategies (CO and reduced sulfur oxidation) and obtained new hints into the microbial taxa actively involved in other biogeochemical processes in coastal shelf waters, such as Can. A. thalassa in nitrogen fixation, OM60/NOR5 in DMSP uptake, and Euryarchaeota and Ostreococcus in P cycling.

\section{DATA AVAILABILITY STATEMENT}

Raw sequences analyzed for this study can be found in the European Nucleotide Archive under the following accession numbers: ERS1836494-ERS1836501.

\section{AUTHOR CONTRIBUTIONS}

LA-S and XM conceived the study. LA-S conducted the sample collection and laboratory processing, and wrote the manuscript 
with input from all other authors. LA-S and JG analyzed the transcriptomic data.

\section{FUNDING}

This research was funded by the Marie Curie European Reintegration Grant FUNDIVERSITY' (FP7, Grant Agreement 268331) to LA-S, the time-series program RADIALES from the Spanish Institute of Oceanography (IEO) and by the Spanish Ministry of Economy, Industry and Competitiveness ("Juan de la Cierva" and "Ramon y Cajal" RYC-2012-11404 research contracts to LA-S and project CTM2016-80095C2-2-R to JG).

\section{REFERENCES}

Akram, N., Palovaara, J., Forsberg, J., Lindh, M. V., Milton, D. L., Luo, H., et al. (2013). Regulation of proteorhodopsin gene expression by nutrient limitation in the marine bacterium Vibrio sp. AND4. Environ. Microbiol. 15, 1400-1415. doi: 10.1111/1462-2920.12085

Alonso-Sáez, L., Díaz-Pérez, L., and Morán, X. A. G. (2015). The hidden seasonality of the rare biosphere in coastal marine bacterioplankton. Environ. Microbiol. 17, 3766-3780. doi: 10.1111/1462-2920.12801

Alonso-Sáez, L., Morán, X. A. G., and Clokie, M. R. J. (2018). Low activity of lytic pelagiphages in coastal marine waters. ISME J. 12, 2100-2102. doi: 10.1038/ s41396-018-0185-y

Alonso-Sáez, L., Waller, A. S., Mende, D. R., Bakker, K., Farnelid, H., Yager, P. L., et al. (2012). Role for urea in nitrification by polar marine Archaea. Proc. Natl. Acad. Sci. U.S.A. 109, 17989-17994. doi: 10.1073/pnas.120191 4109

Altschul, S. F., Gish, W., Miller, W., Myers, E. W., and Lipman, D. J. (1990). Basic local alignment search tool. J. Mol. Biol. 215, $403-410$.

Arandia-Gorostidi, N., Huete-Stauffer, T. M., Alonso-Sáez, L., and Morán, X. A. G. (2017). Testing the metabolic theory of ecology with marine bacteria: different temperature sensitivity of major phylogenetic groups during the spring phytoplankton bloom. Environ. Microbiol. 19, 4493-4505. doi: 10.1111/14622920.13898

Aylward, F. O., Eppley, J. M., Smith, J. M., Chavez, F. P., Scholin, C. A., and DeLong, E. F. (2015). Microbial community transcriptional networks are conserved in three domains at ocean basin scales. Proc. Natl. Acad. Sci. U.S.A. 112, 5443-5448. doi: 10.1073/pnas.1502883112

Bayer, B., Vojvoda, J., Offre, P., Alves, R. J. E., Elisabeth, N. H., Garcia, J. A. L., et al. (2016). Physiological and genomic characterization of two novel marine thaumarchaeal strains indicates niche differentiation. ISME J. 10, 1051-1063. doi: 10.1038/ismej.2015.200

Bode, A., Casas, B., Fernández, E., Marañón, E., Serret, P., and Varela, M. (1996). Phytoplankton biomass and production in shelf waters off NW Spain: spatial and seasonal variability in relation to upwelling. Hydrobiologia 341, 225-234. doi: 10.1007/bf00014687

Bombar, D., Paerl, R. W., and Riemann, L. (2016). Marine non-cyanobacterial diazotrophs: moving beyond molecular detection. Trends Microbiol. 24, 916-927. doi: 10.1016/j.tim.2016.07.002

Buchan, A., González, J. M., and Moran, M. A. (2005). Overview of the marine Roseobacter lineage. Appl. Environ. Microbiol. 71, 5665-5677. doi: 10.1128/aem. 71.10.5665-5677.2005

Cabello, A. M., Cornejo-Castillo, F. M., Raho, N., Blasco, D., Vidal, M., Audic, S., et al. (2016). Global distribution and vertical patterns of a prymnesiophytecyanobacteria obligate symbiosis. ISME J. 10, 693-706. doi: 10.1038/ismej.2015. 147

Church, M. J., Wai, B., Karl, D. M., and DeLong, E. F. (2010). Abundances of crenarchaeal amoA genes and transcripts in the Pacific Ocean. Environ. Microbiol. 12, 679-688. doi: 10.1111/j.1462-2920.2009.02108.x

\section{ACKNOWLEDGMENTS}

We are grateful to the crew of RV “José de Rioja” and colleagues from IEO Gijón/Xixón for their help with the RNA samples collection, especially to N. Arandia-Gorostidi and T. M. HueteStauffer. Bioinformatics analyses were supported by CESGA (Centro de Supercomputación de Galicia).

\section{SUPPLEMENTARY MATERIAL}

The Supplementary Material for this article can be found online at: https://www.frontiersin.org/articles/10.3389/fmicb. 2020.00465/full\#supplementary-material

Collier, J. L., Baker, K. M., and Bell, S. L. (2009). Diversity of urea-degrading microorganisms in open-ocean and estuarine planktonic communities. Environ. Microbiol. 11, 3118-3131. doi: 10.1111/j.1462-2920.2009.02016.x

Cordero, P. R. F., Bayly, K., Leung, P. M., Huang, C., Islam, Z. F., Schittenhelm, R. B., et al. (2019). Atmospheric carbon monoxide oxidation is a widespread mechanism supporting microbial survival. ISME J. 13, 2868-2881. doi: 10.1038/ s41396-019-0479-8

Cunliffe, M. (2013). Physiological and metabolic effects of carbon monoxide oxidation in the model marine bacterioplankton Ruegeria pomeroyi DSS-3. Appl. Environ. Microbiol. 79, 738-740. doi: 10.1128/AEM.02466- 12

Eddy, S. R. (2008). A probabilistic model of local sequence alignment that simplifies statistical significance estimation. PLoS Comput. Biol. 2008:e1000069. doi: 10. 1371/journal.pcbi.1000069

Ferrera, I., Borrego, C. M., Salazar, G., and Gasol, J. M. (2014). Marked seasonality of aerobic anoxygenic phototrophic bacteria in the coastal NW Mediterranean Sea as revealed by cell abundance., pigment concentration and pyrosequencing of pufM gene. Environ. Microbiol. 16, 2953-2965. doi: 10.1111/1462-2920. 12278

Ferrera, I., Sebastián, M., Acinas, S. G., and Gasol, J. M. (2015). Prokaryotic functional gene diversity in the sunlit ocean: stumbling in the dark. Curr. Opin. Microbiol. 25, 33-39. doi: 10.1016/j.mib.2015.03.007

Francis, C., Roberts, K., Beman, J. M., Santoro, A. E., and Oakley, B. B. (2005). Ubiquity and diversity of ammonia-oxidizing archaea in water columns and sediments of the ocean. Proc. Natl. Acad. Sci. U.S.A. 102, 14683-14688. doi: $10.1073 /$ pnas.0506625102

Galand, P. E., Gutiérrez-Provecho, C., Massana, R., Gasol, J. M., and Casamayor, E. O. (2010). Inter-annual recurrence of archaeal assemblages in the coastal NW Mediterranean Sea (Blanes Bay Microbial Observatory). Limnol. Oceanogr. 55:2117. doi: 10.4319/lo.2010.55.5.2117

Georges, A. A., El-Swais, H., Craig, S. E., Li, W. K. W., and Walsh, D. A. (2014). Metaproteomic analysis of a winter to spring succession in coastal northwest Atlantic Ocean microbial plankton. ISME J. 8, 1301-1313. doi: 10.1038/ismej. 2013.234

Giebel, H.-A., Wolterink, M., Brinkhoff, T., and Simon, M. (2019). Complementary energy acquisition via aerobic anoxygenic photosynthesis and carbon monoxide oxidation by Planktomarina temperata of the Roseobacter group. FEMS Microbiol. Ecol. 95:fiz050. doi: 10.1093/femsec/fiz050

Gifford, S. M., Sharma, S., Booth, M., and Moran, A. (2013). Expression patterns reveal niche diversification in a marine microbial assemblage. ISME J. 7, 281-298. doi: 10.1038/ismej.2012.96

Gifford, S. M., Sharma, S., and Moran, M. A. (2014). Linking activity and function to ecosystem dynamics in a coastal bacterioplankton community. Front. Microbiol. 5:185. doi: 10.3389/fmicb.2014.00185

Gifford, S. M., Sharma, S., Rinta-Kanto, J. M., and Moran, M. A. (2011). Quantitative analysis of a deeply sequenced marine microbial metatranscriptome. ISME J. 5, 461-472. doi: 10.1038/ismej.2010.141

Gilbert, J. A., and Dupont, C. L. (2011). Microbial metagenomics: beyond the genome. Ann. Rev. Mar. Sci. 3, 347-371. doi: 10.1146/annurev-marine-120709142811 
Giovannoni, S. J., Bibbs, L., Cho, J.-L., Stapels, M. D., Desiderio, R., Vergin, K. L., et al. (2005). Proteorhodopsin in the ubiquitous marine bacterium SAR11. Nature 438, 82-85. doi: 10.1038/nature04032

Gómez-Consarnau, L., González, J. M., Coll-Lladó, M., Gourdon, P., Pascher, T., Neutze, R., et al. (2007). Light stimulates growth of proteorhodopsin-containing marine Flavobacteria. Nature 445, 210-213. doi: 10.1038/nature05381

Gómez-Consarnau, L., González, J. M., Riedel, T., Jaenicke, S., Wagner-Döbler, I., Sañudo-Wilhelmy, S. A., et al. (2016). Proteorhodopsin light-enchanced growth linked to vitamin-B1 acquisition in marine Flavobacteria. ISME J. 10, 1102-1112. doi: 10.1038/ismej.2015.196

Hollibaugh, J. T., Gifford, S. M., Ross, M. J., and Tolar, B. B. (2014). Seasonal variation in the metratranscriptomes of a Thaumarchaeota population from SE USA coastal waters. ISME J. 8, 685-698. doi: 10.1038/ismej.2013.171

Huson, D. H., Auch, A. F., Qi, J., and Schuster, S. C. (2007). MEGAN analysis of metagenomic data. Genome Res. 17, 377-386. doi: 10.1101/gr.5969107

Jeanthon, C., Boeuf, D., Dahan, O., Le Gall, F., Garczarek, L., Bendif, E. M., et al. (2011). Diversity of cultivated and metabolically active aerobic anoxygenic phototrophic bacteria along an oligotrophic gradient in the Mediterranean Sea. Biogeosciences 8, 1955-1970. doi: 10.5194/bg-8-1955-2011

King, G. M., and Weber, C. F. (2007). Distribution., diversity and ecology of aerobic CO-oxidizing bacteria. Nat. Rev. Microbiol. 5, 107-118. doi: 10.1038/ nrmicro1595

Krupke, A., Mohr, W., LaRoche, J., Fuchs, B. M., Amann, R. I., and Kypers, M. M. M. (2015). The effect of nutrients on carbon and nitrogen fixation by the UCYN-A-haptophyte symbiosis. ISME J. 9, 1635-1647. doi: 10.1038/ismej. 2014.253

Lami, R., Ghiglione, J. F., Desdevises, Y., West, N., and Lebaron, P. (2009). Annual patterns of presence and activity of marine bacteria monitored by $16 \mathrm{~S}$ rDNA16S rRNA fingerprints in the coastal NW Mediterranean Sea. Aquat. Microbial. Ecol. 54, 199-210. doi: 10.3354/ame01264

Luo, H., Benner, R., Long, R. A., and Hu, J. (2009). Subcellular localization of marine bacterial alkaline phosphatases. Proc. Natl. Acad. Sci. U.S.A. 106, 21219-21223. doi: 10.1073/pnas.0907586106

Malmstrom, R. R., Kiene, R. P., Vila, M., and Kirchman, D. L. (2005). Dimethylsulfoniopropionate (DMSP) assimilation by Synechococcus in the Gulf of Mexico and Northwest Atlantic Ocean. Limnol. Oceanogr. 50, 1924-1931. doi: 10.4319/lo.2005.50.6.1924

Martínez-Pérez, C., Mohr, W., Löscher, C. R., Dekaezemacker, J., Littmann, S. Yilmaz, P., et al. (2016). The small unicellular diazotrophic symbiont., UCYNA., is a key player in the marine nitrogen cycle. Nat. Microbiol. 1:16163. doi: 10.1038/nmicrobiol.2016.163

McCarren, J., Becker, J. W., Repeta, D. J., Shi, Y., Young, C. R., Malmstrom, R. R., et al. (2010). Microbial community transcriptomes reveal microbes and metabolic pathways associated with dissolved organic matter turnover in the sea. Proc. Natl. Acad. Sci. U.S.A. 107, 16420-16427. doi: 10.1073/pnas. 1010732107

Moisander, P. H., Beinart, R. A., Hewson, I., White, A. E., Johnson, K. S., Carlson, C. A., et al. (2010). Unicellular cyanobacterial distributions broaden the oceanic $\mathrm{N}_{2}$ fixation domain. Science 327, 1512-1514. doi: 10.1126/science.1185468

Moran, M. A. (2008). "Genomics and metagenomics of marine prokaryotes," in Microbial Ecology of the Oceans, 2nd Edn, ed. D. L. Kirchman (Hoboken, NJ: Wiley-Blackwell), 91-129. doi: 10.1002/9780470281840.ch4

Moran, M. A., Buchan, A., Gonzalez, J. M., Heidelberg, J. F., Whitman, W. B., Kiene, R. P., et al. (2004). Genome sequence of Silicibacter pomeroyi reveals adaptations to the marine environment. Nature 432, 910-913. doi: 10.1038/ nature 03170

Moran, M. A., Satinsky, B., Gifford, S. M., Luo, H., Rivers, A., Chan, L.-K., et al. (2013). Sizing up metatranscriptomics. ISME J. 7, 237-243. doi: 10.1038/ismej. 2012.94

Morán, X. A. G., Alonso-Sáez, L., Nogueira, E., Ducklow, H. W., González, N., López-Urrutia, A., et al. (2015). More, smaller bacteria in response to ocean's warming. Proc. Biol. Sci. 282:20150371. doi: 10.1098/rspb.2015.0371

Morán, X. A. G., Calvo-Díaz, L., Arandia-Gorostidi, N., and Huete-Stauffer, T. M. (2018). Temperature sensitivities of microbial plankton net growth rates are seasonally coherent and linked to nutrient availability. Environ. Microbiol. 20, 3798-3810. doi: 10.1111/1462-2920.14393

Motard-Côté, J., Levasseur, M., Scarratt, M. G., Michaud, S., Gratton, Y., Rivkin, R. B., et al. (2012). Distribution and metabolism of dimethylsulfoniopropionate
(DMSP) and phylogenetic affiliation of DMSP-assimilating bacteria in northern Baffin Bay/Lancaster sound. J. Geophys. Res. 117:C00G11. doi: 10.1029/ 2011JC007330

Muñoz-Marín, M. C., Shilova, I. N., Shi, T., Farnelid, H., Cabello, A. M., and Zehr, J. P. (2019). The transcriptional cycle is suited to daytime N2 fixation in the Unicellular cyanobacterium "Candidatus Atelocyanobacterium Thalassa" (UCYN-A). mBio 10:e2495-18. doi: 10.1128/mBio.02495-18

Ottesen, E. A., Young, C. R., Gifford, S. M., Eppley, J. M., Marin, R., Schuster, S. C., et al. (2014). Multispecies diel transcriptional oscillations in open ocean heterotrophic bacterial assemblages. Science 345, 207-212. doi: 10.1126/science. 1252476

Palovaara, J., Akram, N., Baltar, F., Bunse, C., Forsberg, J., Pedrós-Alió, C., et al. (2014). Stimulation of growth by proterhodopsin phototrophy involves regulation of central metabolic pathways in marine planktonic bacteria. Proc. Natl. Acad. Sci. U.S.A. 111:E3650. doi: 10.1073/pnas.140261 7111

Pitcher, A., Wuchter, C., Siedenberg, K., Schouten, S., and Damsté, J. S. S. (2011). Crenarchaeol tracks winter blooms of ammonia-oxidizing Thaumarchaeota in the coastal North Sea. Limnol. Oceanogr. 56, 2308-2318. doi: 10.4319/lo.2011. 56.6.2308

Poretsky, R. S., Bano, N., Buchan, A., LeCleir, G. R., Kleikemper, J., Pickering, M., et al. (2005). Analysis of microbial gene transcripts in environmental samples. Appl. Environ. Microbiol. 71, 4121-4126. doi: 10.1128/aem.71.7.4121-4126. 2005

Poretsky, R. S., Gifford, S. M., and Rinta-Kanto, J. (2009a). Analyzing gene expression from marine microbial communities using environmental transcriptomics. J. Vis. Exp. 2009:1086. doi: 10.3791/1086

Poretsky, R. S., Hewson, I., Allen, A. E., and Zehr, J. P. (2009b). Comparative day/night metatranscriptomic analysis of microbial communities in the North Pacific subtropical gyre. Environ. Microbiol. 11, 1358-1375. doi: 10.1111/j.14622920.2008.01863.x

Qin, W., Amin, S. A., Martens-Habbena, W., Walker, C. B., Urakawa, H., Devol, A. H., et al. (2014). Marine ammonia-oxidizing archaeal isolates display obligate mixotrophy and wide ecotypic variation. Proc. Natl. Acad. Sci. U.S.A. 111, 12504-12509. doi: 10.1073/pnas.1324115111

Riedel, T., Tomasch, J., Buchholz, I., Jacobs, J., Kollenberg, M., Gerdts, G., et al. (2010). Constitutive Expression of the Proteorhodopsin gene by a Flavobacterium strain representative of the proteorhodopsin-producing microbial community of the North Sea. Appl. Environ. Microbiol. 76, 31873197. doi: 10.1128/AEM.02971-09

Salazar, G., Paoli, L., Alberti, A., Huerta-Cepas, J., Ruscheweyh, H.-J., Cuenca, M., et al. (2019). Gene expression changes and community turnover differentially shape the Global Ocean metatranscriptome. Cell 179, 1068-1083. doi: 10.1016/ j.cell.2019.10.014

Sebastián, M., and Ammerman, J. W. (2009). The alkaline phosphatase PhoX is more widely distributed in marine bacteria than the classical PhoA. ISME J. 3, 563-572. doi: 10.1038/ismej.2009.10

Sieradzki, E. T., Fuhrman, J. A., Rivero-Calle, S., and Gómez-Consarnau, L. (2018). Proteorhodopsins dominate the expression of phototrophic mechanisms in seasonal and dynamic marine picoplankton communities. PeerJ 6:e5798. doi: 10.7717/peerj.5798

Sintes, E., Bergauer, K., De Corte, D., Yokokawa, T., and Herndl, G. J. (2013). Archaeal amoA gene diversity points to distinct biogeography of ammoniaoxidizing Crenarchaeota in the ocean. Environ. Microbiol. 15, 1647-1658. doi: 10.1111/j.1462-2920.2012.02801.x

Sintes, E., De Corte, D., Haberleitner, E., and Herndl, G. J. (2016). Geographic distribution of archaeal ammonia oxidizing ecotypes in the Atlantic Ocean. Front. Microb. 7:77. doi: 10.3389/fmicb.2016.00077

Solomon, C. M., Collier, J. L., Berg, G. M., and Gilbert, P. M. (2010). Role of urea in microbial metabolism in aquatic systems: a biochemical and molecular review. Aquat. Microbiol. Ecol. 59, 67-88. doi: 10.3354/ame01390

Steindler, L., Schwalbach, M. S., Smith, D. P., Chan, F., and Giovanonni, S. J. (2011). Energy starved Candidatus Pelagibacter ubique substitutes light-mediated ATP production for endogenous carbon respiration. PLoS One 6:e19725. doi: 10. 1371/journal.pone.0019725

Sun, L., Curson, A. R. J., Todd, J. D., and Johnston, A. W. B. (2011). Diversity of DMSP transport in marine bacteria, revealed by genetic analyses. Biogeochemistry 110, 121-130. doi: 10.1007/s10533-011-9666-z 
Thompson, A. W., Foster, R. A., Krupke, A., Carter, B. J., Musat, N., Vaulot, D., et al. (2012). Unicellular cyanobacterium symbiotic with a single-celled eukaryotic alga. Science 337, 1546-1550. doi: 10.1126/science.1222700

Tolar, B. B., Powers, L. C., Miller, W. L., Wallsgrove, N. J., Popp, B. N., and Hollibaugh, J. T. (2016). Ammonia oxidation in the ocean can be inhibited by nanomolar concentrations of hydrogen peroxide. Front. Mar. Sci. 3:237. doi: $10.3389 /$ fmars.2016.00237

Turk-Kubo, K. A., Achilles, K. M., Serros, T. R., Ochiai, M., Montoya, J. P., and Zehr, J. P. (2012). Nitrogenase (nifH) gene expression in diazotrophic cyanobacteria in the Tropical North Atlantic in response to nutrient amendments. Front. Microbiol. 3:386. doi: 10.3389/fmicb.2012.00386

Venter, J. C., Remington, K., Heidelberg, J. F., Halpern, A. L., Rusch, D., Eisen, J. A., et al. (2004). Environmental genome shotgun sequencing of the Sargasso Sea. Science 304, 66-74. doi: 10.1126/science.1093857

Vila, M., Simó, R., Kiene, R. P., Pinhassi, J., González, J. M., Moran, M. A., et al. (2004). Use of microautoradiography combined with fluorescence in situ hybridization to determine dimethylsulfoniopropionate incorporation by marine bacterioplankton taxa. Appl. Environ. Microbiol. 70, 4648-4657. doi: 10.1128/aem.70.8.4648-4657.2004

Vila-Costa, M., Rinta-Kanto, J. M., Sun, S., Sharma, S., Poretsky, R., and Moran, M. A. (2010). Transcriptomic analysis of a marine bacterial community enriched with dimethylsulfoniopropionate. ISME J. 4, 1410-1420. doi: 10.1038/ ismej.2010.62

Voget, S., Wemheuer, B., Brinkhoff, T., Vollmers, J., Dietrich, S., Giebel, H.-A., et al. (2015). Adaptation of an abundant Roseobacter RCA organism to pelagic systems revealed by genomic and transcriptomic analyses. ISME J. 9, 371-384. doi: 10.1038/ismej.2014.134

Wagner-Döbler, I., and Biebl, H. (2006). Environmental biology of the marine Roseobacter lineage. Ann. Rev. Microbiol. 60, 255-280.

Walker, C. B., de la Torre, J. R., Klotz, M. G., Urakawa, H., Pinel, N., Arp, D. J., et al. (2010). Nitrosopumilus maritimus genome reveals unique mechanisms for nitrification and autotrophy in globally distributed marine Crenarchaea. Proc. Natl. Acad. Sci. U.S.A. 107, 8818-8823. doi: 10.1073/pnas.0913533107

Ward, B. B., Capone, D. G., and Zehr, J. P. (2007). What's new in the Nitrogen Cycle? Oceanography 20, 101-109. doi: 10.5670/oceanog.2007.53
Wattam, A. R., Abraham, D., Dalay, O., Disz, T. L., Driscoll, T., Gabbard, J. L., et al. (2013). PATRIC, the bacterial bioinformatics database and analysis resource. Nucleic Acid Res. 42, D581-D591.

Wuchter, C., Abbas, B., Coolen, M. J. L., Herfort, L., van Bleijswijk, J., Timmers, P., et al. (2006). Archaeal nitrification in the ocean. Proc. Natl. Acad. Sci. U.S.A. 103, 12317-12322. doi: 10.1073/pnas.0600756103

Yoch, D. C. (2002). Dimethylsulfoniopropionate: its sources., role in the marine food web., and biological degradation to dimethylsulfide. Appl. Environ. Microbiol. 68, 5804-5815. doi: 10.1128/aem.68.12.5804-5815.2002

Zehr, J. P. (2011). Nitrogen fixation by marine cyanobacteria. Trends Microbiol. 19, 162-173. doi: 10.1016/j.tim.2010.12.004

Zehr, J. P., Jenkins, B. D., Short, S. M., and Steward, G. F. (2003). Nitrogenase gene diversity and microbial community structure: a cross-system comparison. Environ. Microbiol. 5, 539-554. doi: 10.1046/j.1462-2920.2003.00451.x

Zehr, J. P., and Kudela, R. M. (2011). Nitrogen cycle of the open ocean: from genes to ecosystems. Ann. Rev. Mar. Sci. 3, 197-225. doi: 10.1146/annurev-marine120709-142819

Zhang, C. L., Xie, W., Martin-Cuadrado, B., and Rodríguez-Valera, F. (2015). Marine Group II Archaea, potentially important players in the global ocean carbon cycle. Front. Microbiol. 6:1108. doi: 10.3389/fmicb.2015.01108

Zinser, E. R., Lindell, D., Johnson, Z. I., Futschik, M. E., Steglich, C., Coleman, M. L., et al. (2009). Choreography of the transcriptome, photophysiology, and cell cycle of a minimal photoautotroph, Prochlorococcus. PLoS One 4:e5135. doi: 10.1371/journal.pone.0005135

Conflict of Interest: The authors declare that the research was conducted in the absence of any commercial or financial relationships that could be construed as a potential conflict of interest.

Copyright (C) 2020 Alonso-Sáez, Morán and González. This is an open-access article distributed under the terms of the Creative Commons Attribution License (CC BY). The use, distribution or reproduction in other forums is permitted, provided the original author(s) and the copyright owner(s) are credited and that the original publication in this journal is cited, in accordance with accepted academic practice. No use, distribution or reproduction is permitted which does not comply with these terms. 